\title{
General Context of Smallholder Farmers' Access to Seed of Improved Legume Varieties and Innovation Platform Perspectives
}

\author{
Essegbemon Akpo, Chris O. Ojiewo, Issoufou Kapran, \\ Lucky O. Omoigui, Agathe Diama, and Rajeev K. Varshney
}

\begin{abstract}
The high percentage of farmers $(80-90 \%)$, including the pro-poor in remote areas, who have no access to recently released and high-yielding varieties proves the failure of various seed delivery models implemented so far. The ideal model to grow a crop commodity business to reach farmers in developing countries with seed of improved legume crop varieties has been a hard topic for development organizations. Past studies have shown that the full and balanced integration of multiple stakeholders' knowledge and contexts into the process of agricultural technology development increases the uptake and ownership among end users.
\end{abstract}

\section{Keywords}

Improved legume variety · Productivity of smallholder farming · Seed delivery model $\cdot$ Innovation platform $\cdot$ Sub-Saharan Africa and South Asia

E. Akpo $(\varangle) \cdot$ C. O. Ojiewo

International Crops Research Institute for the Semi-Arid Tropics (ICRISAT), Nairobi, Kenya e-mail: e.akpo@cgiar.org

I. Kapran · A. Diama

RP-WCA, ICRISAT, Bamako, Mali

L. O. Omoigui

International Institute of Tropical Agriculture, Kano, Nigeria

R. K. Varshney

Research Program - Genetic Gains, International Crops Research Institute for the Semi-Arid Tropics (ICRISAT), Patancheru, India 


\subsection{Introduction}

Seed is the single most important input in crop production. The lack of quality seed limits smallholder farmers' production and productivity of developing countries in sub-Saharan Africa (SSA). Most precious asset of smallholder farmers passed on from generation to generation, the seed alone as input, is estimated to contribute up to $20 \%$ of total crop productivity. Despite this, only an average of about $20 \%$ of farmers in sub-Saharan Africa use seeds of improved varieties. The availability of seed of improved varieties supported by other inputs and services is important for increased crop yield and agricultural production and in most cases guarantees household food security. Good supply systems ensure farmers' or households sustained ability to sufficient quality of the desired types of seed at the right time (Kiwanuka and Kintu 2004). The average legume crop yield attained by smallholder farmers in developing countries in SSA is still low (below $1000 \mathrm{~kg} / \mathrm{ha}$ ) compared to the potential yield under good management. For grain legumes, e.g. groundnut, cowpea and chickpea, the productivity is linked to limited access to seed of improved varieties for planting. The low productivity is also linked to harsh and unpredictable weather conditions as well as a complex of insect pests and disease problems that the old varieties can no longer withstand, knowing that many of these old ruling varieties are aged between 20 and 50 years and beyond when new pests and diseases are constantly evolving with time. The pressure of other biotic stresses makes the situation even worse as the parasitic weeds such as Striga gesnerioides (Wild.) Vatke and Alectra vogelii (Benth.) can potentially reduce the yield of legume crops by 50\% (Mahmoud et al. 2013; Ayeni et al. 2017). Improved, climate-resilient, and high-yielding crop varieties offer a practical and sustainable way of adapting to the harsh environmental conditions that are characteristic of dryland regions. For example, while the national average for most legume crops is still below $1000 \mathrm{~kg}$, the new improved varieties have been tested to produce two to threefold over the current yield farmers get with most old ruling varieties. In recent years, many new climateresilient legume varieties specifically bred for increased tolerance to traits associated with a variable and changing climate, with high productivity output market-fit, and responsive to the farmer need have been developed and released by national agricultural research systems with support of the Consortium of International Agricultural Research Centers (CGIAR), e.g. ICRISAT, IITA, CIAT. Up to recently, many of these varieties were unknown to the vast majority of smallholder farmers in the dryland farming communities, indicative of a weak seed system. Improved varieties adoption has scored low in most developing countries of SSA (Garbero et al. 2018).

The high percentage of farmers (80-90\%), including the pro-poor in remote areas, who have no access to recently released and high-yielding varieties proves the failure of various seed delivery models implemented so far. For decades, a variety of seed and other technology delivery models have been developed with intention to serve the highest number of smallholder farmers with improved technologies. The rate of replacement of old ruling varieties with new improved ones is still lower than development partners would like to see. The state-controlled model with extension 
services distributing improved seed is no longer adequate to serve the ever-growing number of smallholder farmers widely spread in rural communities. The NGOs' community approach model has not reaped at scale either. The community seed production and distribution efforts usually end when projects come to an end. The private seed companies alone have not been very effective in targeting farmers in remote areas. The traditional location of private seed companies falls short to involve small farmers with inconsistent seed demand from one year to another. The fitness of old ruling varieties to farmer contexts and the output market was not good enough to attract large and consistent consumer demand. For open pollinated varieties, and self-pollinated food legume crops, farmers hardly renew seed and varieties annually and plant most of their plot to home-saved seed. All these challenges make it difficult for the commodity value chain to grow into large business opportunities for farmers and other actors to sustain their daily livelihood.

\subsection{Role of Innovation Platform in Change Facilitation}

Developing more innovative mechanisms building on the strengths of currently existing seed technology delivery models is critical. The ideal model to grow a commodity business to reach farmers in developing countries with improved seed of legume crop varieties has been a hard topic for development organizations. Past studies have shown that the full and balanced integration of multiple stakeholders' knowledge and contexts into the process of agricultural technology development increases the uptake and ownership among end users (Akpo et al. 2015). During the past decade, Innovation Platform (IP) has been put forward as a social space for information sharing and learning for innovation by various stakeholders who have interest in solving a value chain challenge, be it, a problem or an opportunity. Innovation platform gathers relevant stakeholders who meet physically or virtually to address issues of common interest. The outcomes of innovation platform interactions and participation bring benefits to every actor involved through three key principles: (1) the recognition of the complexities of the issues that affect sustainable productivity, production, processing, marketing and utilization of agricultural commodity; (2) the integration of research and development along the commodity value chain whereby productivity, market outlets, management of natural resources, policy ecosystems, product development, gender and youth are purposely balanced; (3) the use of innovation system approach as core intervention strategy where various actors contribute collectively to identify problems, understand the context, explore relevant solutions, implement, monitor and assess the solutions for adjustment to make a difference in the lives of stakeholders and communities involved (Adekunle et al. 2013). Innovation platform can operate at operational level or strategic level. The operational platforms are located at the grassroots' level, under the auspices of strategic platform set up at higher level to define strategic orientations, options and axes. The roles of the operational IP are joint diagnostic with the different ground actors, validation of technological options through demonstrations, validation of mechanisms to access different services, e.g. credit, information, market, support to 
farmers' organizations, and facilitate interaction between farmers through crossvisit, exchange days, field days, facilitate interactions between ground actors for experience sharing and learning, build actors' capacity (farmers, processors, traders, etc.). The roles of the strategic platforms are to engage facilitators (researchers, extensionists, NGO professionals) to better support IP, facilitate experience sharing among facilitators to enforce mutual learning, create institutional support to the IP, negotiate better market access to IP members, facilitate mechanisms to access various services, i.e. credits, markets, technical supports. Most of the platforms reported in this book are operational platforms working closely with farming communities.

The use of innovation platform to enhance smallholder farmers' access to seed of improved varieties of legume crops through the Tropical Legumes phase III (TL III) project represents a major initiative. The outcomes of the Tropical Legumes project interventions deserved to be shared with practitioners and other professionals for learning and reflections to inform future technology delivery initiatives. The seed sector is a full value chain that requires collective actions among actors along the seed value chain to deliver the various seed classes, i.e. breeder or pre-basic seed, foundation or basic seed, certified and quality declared seeds. These different seed classes are handled by various actors whose interactions need proper coordination to these important planting materials in a sustainable manner. Specifically, for early generation seed of legume crops, timeliness of availability is a major challenge that only concerted efforts of various players can solve. This is the main reason the TL III project selected IP as the main mechanism to deliver its seed delivery component.

\subsection{Aim of this Book}

The aim of this book is to share with the wider research, development and scientific communities, the experiences of TL III in facilitating smallholder farmers' access to seed of improved legume varieties through innovation platforms in seven developing countries, i.e. six sub-Saharan African countries Burkina Faso, Ghana, Mali, Nigeria in West Africa, Ethiopia, Tanzania in East Africa and India for the past 12 years (Monyo and Varshney 2016). In this book, we used the concepts innovation platform, multi-stakeholder platform and platform concurrently meaning, a physical or virtual space for interactions, learning and innovation along the legume commodity value chains for different actors who have interest to have a challenge resolved.

\subsection{Structure of the Book}

This book is organized into 14 Chapters. Chapter 1 is an introductory general context of smallholder farmers' access to legume seed. Chapter 2 presents the groundnut seed production and distribution through the Southern Groundnut Platform (SGP) in Tanzania. The power of SGP to leverage different categories of 
knowledge brokers for farming practices improvement is presented. The observed increase in groundnut production and business over years is highlighted. Chapter 3 shows the progress made in groundnut value chain in Burkina Faso thanks to seed of improved varieties. The quality declared seed and certified seeds produced and sold to the local communities at affordable price and in small packs are presented. Chapter 4 sheds light on the achievements made in groundnut production and marketing systems with male and female seed producers in Mali. Kolokani platform contributions to groundnut seed value chain and farmers' relief in seed acquisition have been synthetized and analyzed. Chapter 5 presents the added value gained in seed access through innovation platform using the case of groundnut business development in Ghana. The importance of various actors as sources of high-quality groundnut seed in their communities and beyond in the production and delivery of the new varieties has been presented. The seed farms where improved varieties were planted and managed using good agronomic practices (GAPS) yielding up to $70 \%$ higher than the old varieties and practices are illustrated. Chapter 6 presents one case of the multiple platform experiences for groundnut in Nigeria. The accrued additional and twofold income for innovation platform members during dry and wet seasons thanks to the TLIII interventions is reported. The increasing access by farmers to various services (e.g. improved seeds, extension, credit facilities, market, etc.) and enhanced productivity (farm size, pod and haulm yields) are highlighted. The high adoption rate of improved variety and other GAPs are presented. Chapter 7 shares the experiences of progress imparted on chickpea value chains and seed business through multi-stakeholder platform in Ethiopia. The way the platform strengthened the extension efforts and triggered dissemination of improved chickpea technologies to a large number of farmers is presented. The three to fourfold increased productivity of chickpea by model farmers and the doubling of the national productivity in the last decade in Ethiopia are highlighted. The platform experience on improving access to market for chickpea farmers is shared. Chapter 8 presents the boost to chickpea productivity observed in project areas thanks to seed of improved chickpea varieties in India. It highlights to what extent the seed societies formed in different districts contributed towards strengthening the formal seed system of chickpea by contributing in quality seed of recommended varieties, marketed to institutionalized seed chains. The thousands of partner farmers with direct access to improved seed through farmers seed societies and indirectly through social networks are presented. The way the efforts of the farmers' societies strengthened the informal seed system through farmer-to-farmer horizontal diffusion resulted in area enhancement under the introduced chickpea varieties in the project villages is further elaborated. In Chap. 9, the facilitation of cowpea seed access to remote farming communities in Nigeria is presented. The rapid adoption and use of newly released varieties by farmers as a result of increased awareness of improved varieties through multi-media and user-friendly communication strategies and tools are presented. The connection of community-based seed producers to seed companies and seed companies to research institutions to access early generation seed (EGS) is underlined. The increased production of basic seed, certified/QDS seed of improved cowpea varieties, and twofold yield increase on farmers' field are highlighted. The increase of 
women and youth incomes as a result of seed entrepreneurship is also presented. Chapter 10 proves the effectiveness of innovation platform to build stakeholders capacity and grow cowpea seed business in Mali. It describes how bringing together farmers, distributors, transporters, financial and technical services, and NGOs ensured greater sharing of information and knowledge among the different actors involved in the cowpea seed value chain. It presents the significant results achieved regarding the number of varieties available for farmers, the amount of foundation seeds produced annually, the effectiveness of small seed packs to reach more farmers, the promotional activities and training sessions for farmers in different aspects of the value chain areas. Chapter 11 demonstrates how informal and formal sectors are driving the cowpea seed sector that works for the whole commodity value chain in Burkina Faso. The key role the platforms played in the dissemination of new cowpea varieties through demonstrations, field days, the mass media and social media is underlined. The increasing demand for foundation seeds in Burkina Faso and INERA's Seed Unit sub-contracting platform members to produce foundation seeds as out-growers is presented. Chapter 12 shares the experience of a seed revolving scheme set up for cowpea in Ghana. Each farmer group was supplied with improved variety seed that was paid back after harvesting. Having been trained to produce their own seed, members of the platform were self-reliant in acquiring improved seed and are actively engaged in various operations that sustain their gains after the phased out of projects. Chapter 13 presents the cross-case analysis of the 11 innovation platform experiences in seven countries. It compares the different approaches followed by different countries in the establishment and implementation of multi-stakeholder platforms for supply of improved legume seed to farmers. The reader is provided with insights into the level of success of innovation platforms in the different countries and implications for agricultural technology dissemination to smallholder farmers. Chapter 14 presents the concluding remarks highlighting the progress made through the multi-stakeholder platform in the different countries, the main lessons drawn from TL III experiences and how these can inform future initiatives to facilitate improved agricultural technologies delivery to farmers and other actors along commodity value chains in developing countries.

\section{References}

Adekunle AA, Fatunbi AO, Buruchara R, Nyamwaro S (2013) Integrated agricultural research for development: from concept to practice. Forum for Agricultural Research in Africa (FARA)

Akpo E, Crane AT, Vissoh VP, Tossou CR (2015) Co-production of knowledge in multi-stakeholder processes: analyzing joint experimentation as social learning. J Agric Educ Ext 21(4):369-388

Ayeni DF, Omoigui LO, Ikwebe J (2017) Response of cowpea genotypes to Striga gesnerioides infection under varied phosphorus levels. AASCIT J Biosci 3(5):40-46

Garbero A, Marion P, Brailovskaya V (2018) The impact of the adoption of CGIAR's improved varieties on poverty and welfare outcomes. A systematic review. IFAD Res Ser 33:82

Kiwanuka S, Kintu J (2004) Seed security in Uganda: current status, issues and challenges. Ugandan J Agric Sci 9:17-22

Mahmoud BA, Hamma IL, Abdullahi SS, Adamu Y (2013) Common striga control methods in Nigeria: a review. Int J Agron Agric Res 3(9):26-29 
Monyo E, Varshney R (eds) (2016) Seven seasons of learning and engaging smallholder farmers in the drought-prone areas of sub-Saharan Africa and South Asia through Tropical Legumes, 2007-2014. International Crops Research Institute for the Semi-Arid, Patancheru

Open Access This chapter is licensed under the terms of the Creative Commons Attribution 4.0 International License (http://creativecommons.org/licenses/by/4.0/), which permits use, sharing, adaptation, distribution and reproduction in any medium or format, as long as you give appropriate credit to the original author(s) and the source, provide a link to the Creative Commons license and indicate if changes were made.

The images or other third party material in this chapter are included in the chapter's Creative Commons license, unless indicated otherwise in a credit line to the material. If material is not included in the chapter's Creative Commons license and your intended use is not permitted by statutory regulation or exceeds the permitted use, you will need to obtain permission directly from the copyright holder.

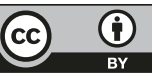

